\title{
COMMENTARY
}

\section{Who needs palliative care?}

\author{
Jessica Simon MB ChB
}

Cite as: CMAJ 2018 March 5;190:E234-5. doi: 10.1503/cmaj.170956

See related article at www.cmaj.ca/lookup/doi/10.1503/cmaj.170604

$\mathbf{F}$ rom its origins in the 1960s, palliative care has served people with "obvious" life-threatening illnesses, such as metastatic cancer and amyotrophic lateral sclerosis. There is an increasing awareness of the benefits of palliative care for those with chronic illnesses (e.g., chronic obstructive pulmonary disease $^{1}$ and renal failure ${ }^{2}$ ), which includes patients with uncertain prognoses (e.g., patients on a liver transplant list $\left.{ }^{3}\right)$. The authors of the linked article explore the relevance of palliative care after an acute life-altering and -threatening event such as a serious stroke.

Kendall and colleagues describe, both quantitatively and qualitatively, the palliative needs of patients with total anterior circulation stroke and their families. They reported that patients with stroke had $60 \%$ mortality at six months, low self-rated quality of life, caregiver strain, and substantial grief and distress of living with a new physical reality. ${ }^{4}$

Patients go through three phases after a stroke: sudden illness and acute hospital admission, rehabilitation and transition to community, and living with major stroke in the community. Kendall and colleagues ${ }^{4}$ also reported that physicians struggled in each phase to support these patients and their families in "hoping for the best and preparing for the worst." Their findings ${ }^{4}$ suggest that many clinicians do not recognize a palliative care approach $^{5}$ as a useful added layer of support after stroke and are not readily delivering this support by screening for and managing patient and family/caregiver distress across multiple domains (i.e., physical, social, psychological, spiritual and existential). The authors of the linked article make important recommendations to enhance generalist skills in the provision of palliative care after stroke that could be applied readily to other acute lifethreatening events; however, they also question whether the term "palliative" is unhelpful as the label for this form of care.

The World Health Organization defines palliative care as "... an approach that improves the quality of life of patients - young and old - and their families who are facing the challenges associated with life-threatening illness. This is achieved through the prevention and relief of suffering, by means of early identification, assessment and treatment of pain and other physical, psychosocial and spiritual distress" (www.who.int/ncds/management/palliative-care /en/). Although this definition is life affirming, for many patients, caregivers $^{6}$ and clinicians, ${ }^{7}$ the term palliative care is synonymous with death. For others, particularly those patients who have

\section{KEY POINTS}

- A palliative care approach includes preventing, screening for and relieving pain and distress associated with the challenges of living with a life-threatening illness.

- This approach can be applied to all life-threatening illnesses, acute and chronic.

- Physicians should consider specialist services in palliative care as an added layer of support for patients and their families that can be provided concurrently with disease-modifying treatment.

received palliative care, early identification, assessment and treatment of pain and other physical, psychosocial and spiritual distress feels like "good medicine."

Some have suggested that "supportive care," ${ }^{8}$ would be a less frightening term for this attentive, holistic approach for patients living with a serious illness. But what is in a name? Might that rose that we call palliative care by any other name still smell of death?

There is something essential in the good medicine of palliative care. By acknowledging that medicine cannot cure all ills, death cannot be endlessly deferred and patients have priorities beyond just living longer, the palliative care approach creates a therapeutic space for expression of hope and of despair, of a wish to prolong life, a wish for good quality of living and, at times, a wish for death to occur. Those skilled in providing a palliative care approach are comfortable with the messy ambivalence, the full swirling spectrum of emotions, logic, physiology and existential uncertainties that accompany those living with a life-threatening illness and anticipating death.

The Center to Advance Palliative Care in the US seeks to normalize specialist palliative care as a part of treating serious illness and to explain that through teamwork, palliative care physicians, nurses, social workers and others "... work together with a patient's other doctors to provide an extra layer of support." (www.capc.org/about/palliative-care). The centre holds that palliative care is appropriate at any age and stage in a serious illness, and can be provided along with curative treatment - without changing the name. Accumulating evidence ${ }^{9}$ and guidelines ${ }^{10-12}$ developed from that evidence suggest that specialist palliative care provided concurrently with disease-modifying treatments 
may confer a benefit to quality of life, without shortening length of life, and may alter use of health resources (e.g., less time in acute care, more time living at home).

In 2016, the Royal College of Physicians and Surgeons of Canada recognized palliative medicine as a subspecialty, and the College of Family Physicians of Canada approved a Certificate of Added Competence in Palliative Care. This change is not meant to take away from the role and abilities that all clinicians have for addressing the distress of patients and families coping with life-threatening illness. It recognizes that specialists in palliative care can support colleagues who manage patients needing complex care; educate health care providers to enhance communication and symptom management competencies; and, through research, determine affordable models of service delivery and community engagement to achieve sustained quality of living despite serious illness at the population level.

In the linked research by Kendall and colleagues, ${ }^{4}$ a family member who felt abandoned by the label palliative is quoted as saying, "One of the staff said 'He's not going to need a wheelchair because he's obviously now palliative care,' which I found very upsetting, that you go from being a priority to being an inconvenience." This is distressing. Pallium Canada (www.pallium.ca), with funding from the federal government, is seeking to educate all care providers to recognize that patients living with life-limiting illnesses are not of themselves palliative. Palliative is not an adjective for a person. Rather, some patients have needs that can be met by applying a palliative approach, including a high priority on feeling valued and remaining connected to their community. Also, clinicians should not use palliative care to define a period of life before death. Those who live and die without prevention and relief of suffering - by means of early identification, assessment and treatment of pain and other physical, psychosocial and spiritual distress - have not received palliative care. They have simply died while receiving questionable quality of care.

The challenging questions for physicians and other health care providers should not be, "What shall we call it?" or "Who should receive palliative care?"; the questions for each patient who is facing the challenges associated with life-threatening illness should be, "Am I providing the palliative care support my patient needs?" and "Is there access to sufficient specialist palliative care resources in my community if needed?".

\section{References}

1. Goodridge DM, Marciniuk DD, Brooks D, et al. End-of-life care for persons with advanced chronic obstructive pulmonary disease: report of a national interdisciplinary consensus meeting. Can Respir J 2009;16:e51-3.

2. Tamura MK, Meier DE. Five policies to promote palliative care for patients with ESRD. Clin J Am Soc Nephrol 2013;8:1783-90.

3. Potosek J, Curry M, Buss M, et al. Integration of palliative care in end-stage liver disease and liver transplantation. J Palliat Med 2014;17:1271-7.

4. Kendall M, Cowey E, Mead G, et al. Outcomes, experiences and palliative care in major stroke: a multicentre, mixed-method, longitudinal study. CMAJ 2018; 190:E238-46.

5. Sawatzky R, Porterfield P, Lee J, et al. Conceptual foundations of a palliative approach: a knowledge synthesis. BMC Palliat Care 2016;15:5.

6. Zimmermann C, Swami N, Krzyzanowska M, et al. Perceptions of palliative care among patients with advanced cancer and their caregivers. CMAJ 2016;188: E217-27.

7. Hui D, Park M, Liu D, et al. Attitudes and beliefs toward supportive and palliative care referral among hematologic and solid tumor oncology specialists. Oncologist 2015;20:1326-32.

8. Hui D, De La Cruz M, Mori M, et al. Concepts and definitions for "supportive care," "best supportive care," "palliative care," and "hospice care" in the published literature, dictionaries, and textbooks. Support Care Cancer 2013;21: 659-85.

9. Bauman JR, Temel JS. The integration of early palliative care with oncology care: the time has come for a new tradition. J Natl Compr Canc Netw 2014;12: 1763-71.

10. Canadian Society of Palliative Care Physicians. Palliative care - Five things physicians and patients should question. Choosing Wisely Canada; 2014. Available: https://choosingwiselycanada.org/palliative-care/ (accessed 2017 Aug. 7).

11. Ferrell BR, Temel JS, Temin S, et al. Integration of palliative care into standard oncology care: American Society of Clinical Oncology Clinical Practice guideline update. J Clin Oncol 2017;35:96-112.

12. McKelvie RS, Moe GW, Cheung A, et al. The 2011 Canadian Cardiovascular Society heart failure management guidelines update: focus on sleep apnea, renal dysfunction, mechanical circulatory support, and palliative care. Can J Cardiol 2011;27:319-38.

Competing interests: None declared.

Affiliation: Department of Oncology, Faculty of Medicine, University of Calgary, Calgary, Alta.

This article was solicited and has not been peer reviewed.

Correspondence to: Jessica Simon, jessica.simon@

albertahealthservices.ca 